Technical University of Gdansk, Faculty of Mechanical Engineering, Narutowicza 11/12, 80-233 Gdansk, Poland, e-mail; asia.zorn@gmail.com

\title{
ALLERGIC REACTIONS AS A DEFENSE OF THE ORGANISM TO THE INFLUENCE OF IMPLANTS COMPONENTS MADE OF STAINLESS STEEL
}

\begin{abstract}
Due to the increasing number of cases of hypersensitivity caused by direct contact with metals, as well as the increasing demand for implants in humans all ages numerous studies on the effects of the impact of implant components are being carried out. The paper presents the phenomenon of etiology of allergy in general terms and in relation to the biomaterials used in medicine. There have been characterized in terms of impact on the body, metallic biomaterials, such as: stainless steels, cobalt based alloys, titanium and its alloys, shape memory alloys and other materials for medical applications (ceramics, plastics, carbon and composite materials), with respect to their reaction in contact with human tissue. The article presents the research included in the MPh of the author, performed on stainless steel.
\end{abstract}

Key words: allergy to implant components, implants

\section{INTRODUCTION}

Contact allergy and eczema are the main types of oversensitive reaction that may occur after implantation of the implant into the human body. Depending on the causes of this type of allergy it occurs in approximately $40 \%$ of adults and $20-30 \%$ of children $[1,2]$. Allergy contact dermatitis is accompanied by the appearance of skin eruptions, which in subsequent stages of the disease may disappear and / or subject to change simultaneously to the emergence of new lesions [1]. This oversensitivity is caused by direct contact with skin allergen (coins containing allergenic metals, jewellery, cosmetics, buckles from belts, buttons alloy), or rather the human organism, eg, by contact with metal implants such as stainless steel containing large amounts of nickel and chromium.

The most common causes of allergies are the increasing pollution of the environment and heredity factors, also feeding the infant or child's exposure to hazardous compounds, such as tobacco smoke and toxic fungi for instance mold (Cladosporium spp.). Additional increase in appearing risk of allergic reactions causes exposure to potential allergens in the first months of life, however, the first contact with the allergen usually does not cause sensitization [3]. Ethology occurrence of hypersensitivity diseases is largely determined by the genetic load, which presents Table. 1 [4].

Allergies can be divided into immediate, namely, that manifests themselves in a few/several minutes, for example, by cold and late, or slowly developing is visible 
through skin lesions (eczema, erythema, vesicles). Delayed allergic reactions may be caused by various metals. In order to detect and determine the oversensitivity a number of studies was carried out to define the cause of allergy (skin tests, blood tests, etc.).

Table 1. Risk of pronouncement of allergy at infants depending on genetic load disease atopic (allergy) [4]

\begin{tabular}{|c|l|c|}
\hline Lp. & \multicolumn{1}{|c|}{ Genetics charges } & $\begin{array}{c}\text { Frequency of occurrence of } \\
\text { allergy [\%] }\end{array}$ \\
\hline 1 & It is not ascertained appearance at fathers and parents atopic and sibling & $5-15$ \\
\hline 2 & One of parents has appearance atopic & $20-40$ \\
\hline 3 & The appearance takes a stand at one of sibling atopic & $25-35$ \\
\hline 4 & The appearance takes a stand at both parents atopic & $40-60$ \\
\hline 5 & Both fathers suffer from the same disease atopic & $60-80$ \\
\hline
\end{tabular}

The most common are skin tests, to perform the deliberate allergen contact with tissue, such as [3]:

- spotlights,

- intradermal,

- flaky known as epidermal .

According to the world medical sources frequency of occurrence of oversensitivity to nickel, chromium and cobalt totals in general population is estimated at $10-15 \%$ [8-10]. An important problem, causing allergy to metals is a surgical technique of doctors and corrosion of implants in the body fluid environment. The damaged prosthesis may release ions of nickel, chromium and cobalt, especially when damage to the layer of chromium oxide [11]. This phenomenon is called metalosis. The period of observation of patients after implantation of metallic implants should be long, especially since the incubation contact allergy to metals can take several months, years, in special cases even several years $[9,12,13]$.

Knowledge of the chemical composition of implant is a key factor to determine allergy to metals, which can be revealed in the various types of eczema, rash-follicle, urticaria. In the most extreme cases, previously acquired sensitivity may lead to loosening of the implant for instance, after hip replacement surgery alloplastick or bone osteonecrosis. Furthermore, it is suspected that coronary restenosis (narrowing after coronary artery surgery) is of etiological origin [14].

Nickel in the human body occurs in an amount of $0.1 \mathrm{ppm}$, deficiency of this element usually result in anemia, are the cause of stunted growth in children and adolescents, however, has exceeded the limit dose effects carcinogenic, toxic and allergic. It occurs in austenitic stainless chromium-nickel-molybdenum, in shape memory alloys, as well as some interest in the warp of cobalt. This element is the allergen most frequently causing contact hypersensitivity among all metals.Nickel allergies, according to the literature data occurs in $13 \%$ of adults and $10 \%$ of young people and $8 \%$ of children, indicating 4 times more frequent symptoms in women [15]. Allergy caused by the metal manifests itself most often pointed nickel eczema [8,16]. Sometimes it turns its manifestation by blisters, which at a later stage of development can transform the erosion. Less frequently observed oversensitivity reactions to nickel are: allergic rhinitis, allergic conjunctivitis, asthma [15]. In some cases, it is noticed lesion occurrance in remote places of the implant. There were cases where present in the socalled dental prostheses. dental nickel, caused an outbreak of eczema in the vicinity of surprising, because such changes (after removal of the prosthesis recessive) were observed for example on the eyelids [7]. Contact dermatitis by nickel was also observed after the application of needles, especially the long hours of drip infusion and needles 
used for acupuncture [9]. The second frequency to cause allergy on metals is chromium. Permited presence of chromium in the human body is $0.2 \mathrm{ppm}$. Deficiency of this element in the body can increase cholesterol and blood sugar, and excess can cause tissue damage and parenchymal organs, and can cause allergy. Chromium in the form of $\mathrm{Cr}^{6+}$ ions and $\mathrm{Cr}^{3+}$ is particularly toxic, because post-operative results including alloplastics cell damage. Allergy to chromium is most common in the elderly, less common in young children in the case occurs occasionally. An interesting aspect of allergy to chromium is the fact that this disease affects men more often than women [7]. This element is one of the basic compounds of stainless steel chromium-nickelmolybdenum and alloy on cobalt basis, which belongs to a group of biomaterials. Chromium can cause skin changes in patients, called the focus of allergic chromium eczema. Symptoms of allergy to this metal are erythematouer, urticarious or vesicula [11].

Cobalt in the human body is present in an amount of about $0.05 \mathrm{ppm}$, a root stimulating hemathopotic processes, assisted by slimming and metabolic processes, but in excess can cause allergic reactions. Allergy to this metal usually coexists with a hypersensitivity to nickel for women and chromium for men, is the most common crossreaction occurring [7,9]. In addition, it was demonstrated that the percentage o men allergic to this metal is $58 \%$, while the percentages of women is $49 \%$ [7].

Titanium is one of the few metals commonly used in implantology. The research proved, that $\mathrm{Ti}$ causes only $0.025 \%$ of the total of allergic reactions [8]. In most cases, sensitivity to this element contributes to the emergency of metalosis or fistula, sometimes manifested in the form of pimples, blush, itching and other reactions in the area of transplantation, which point to allergic reactions [17]. Positive skin patch test confirmed only $2 \%$ of cases of contact allergy on the metals $[18,19]$. Other materials of non-metal origin used for implants, devoid of nickel, chromium and cobalt are considered not causing allergies [20].

\section{MATERIALS AND METHODS}

Research was carried out on stainless steel. Tests have been imposed directly before sticking on adhesive tape on the body of the patient directly. The patch tests were applied according to the directions the IDCR with the chosen allergic compounds to the body - Ni, Cr, Co, V, Ti. The removal of the tests and the first examining them was performed 48h, 72h and last $96 \mathrm{~h}$. Research was carried out on Orthopedic Ward in Hospital in Inowroclaw (Poland).

The following examples illustrate the allergic properties of chromium and nickel observed on the patient's skin after placing metal implants in the human body.

Among patients with renal bone adhesion (Fig.1) some signs of allergy have been found to chromium and nickel in implants made of stainless steels.

Tissue after the removal of the knee implant were collected for histopathological examination. The large changes in the form of cysts filled with bacteria were observed, in the Fig. 2.

In a male patient who had implanted the implant of the hip-joint made of stainless steel were indicated oversensitivity to chromium, which appeared within the first day of implantation. Photos below show the reactions of the tests carried out in $48 \mathrm{~h}, 72 \mathrm{~h}, 96 \mathrm{~h}$ (Fig. 3 A, B, C). It can be noticed that hypersensitivity to chromium in this case was 
increasing and the removal of the implant was urgently necessary. After 96 hours, erythema reached the size of $2 \mathrm{~cm} \times 2 \mathrm{~cm}$.

Another interesting case is a man allergic to chromium and nickel. After 72 hours from implantation of hip-joint replacement a delicate erythema appeared. By contrast, in 96 hour erythema has already spilled into shape (Fig. 4). Histopathological images showed granular tissue in the vicinity of the implant (Fig. 5).

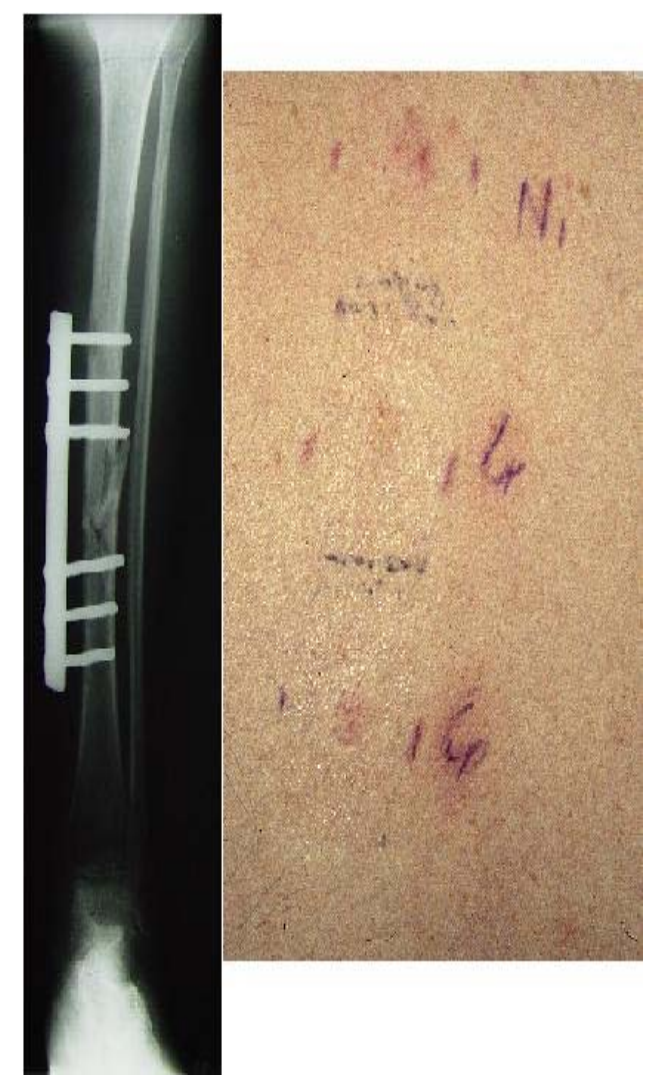

Fig. 1. Complex fracture by method ZESPOL (fig. left). Hypersensitivity to chromium and nickel expressed by the patch tests (fig. Right)

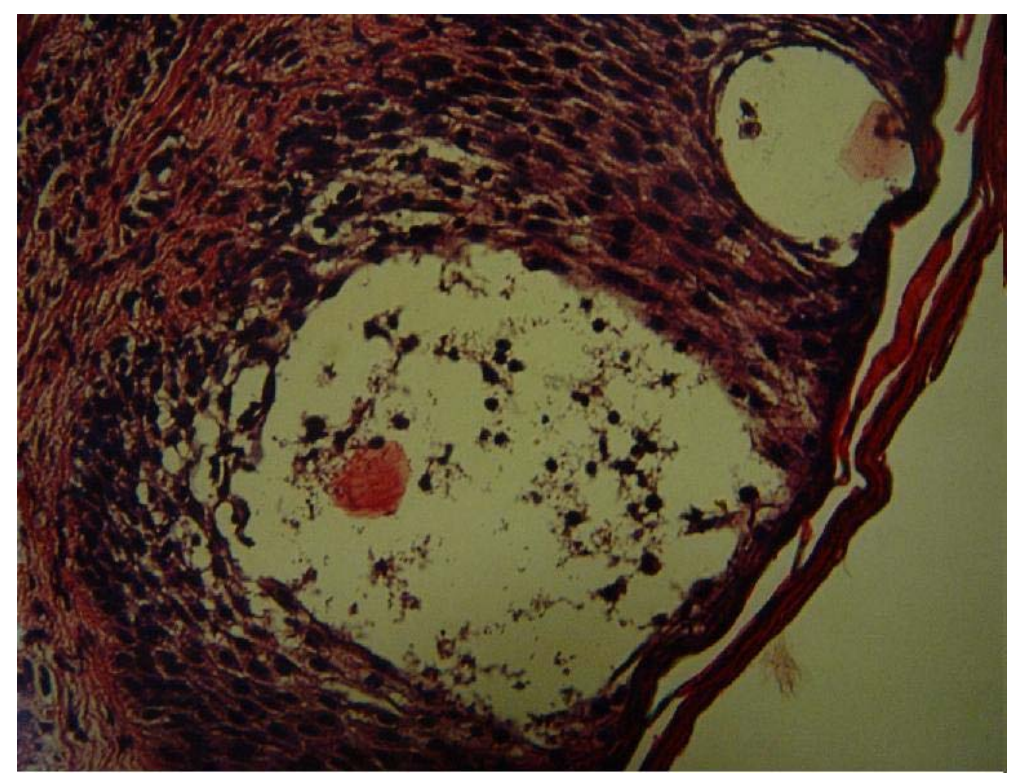

Fig. 2. Tissue with cysts filled with bacteria 


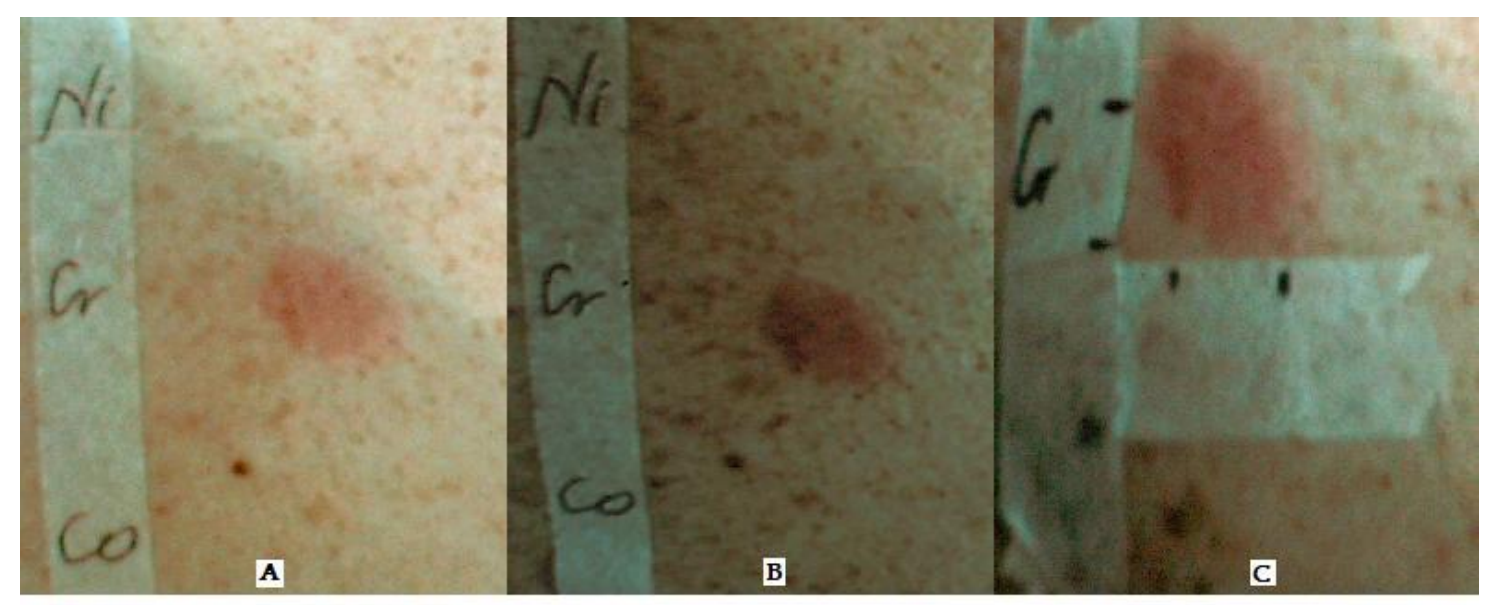

Fig. 3. Allergy reactions to chromium after test preformed at $48 \mathrm{~h}, 72 \mathrm{~h}$ and $96 \mathrm{~h}$

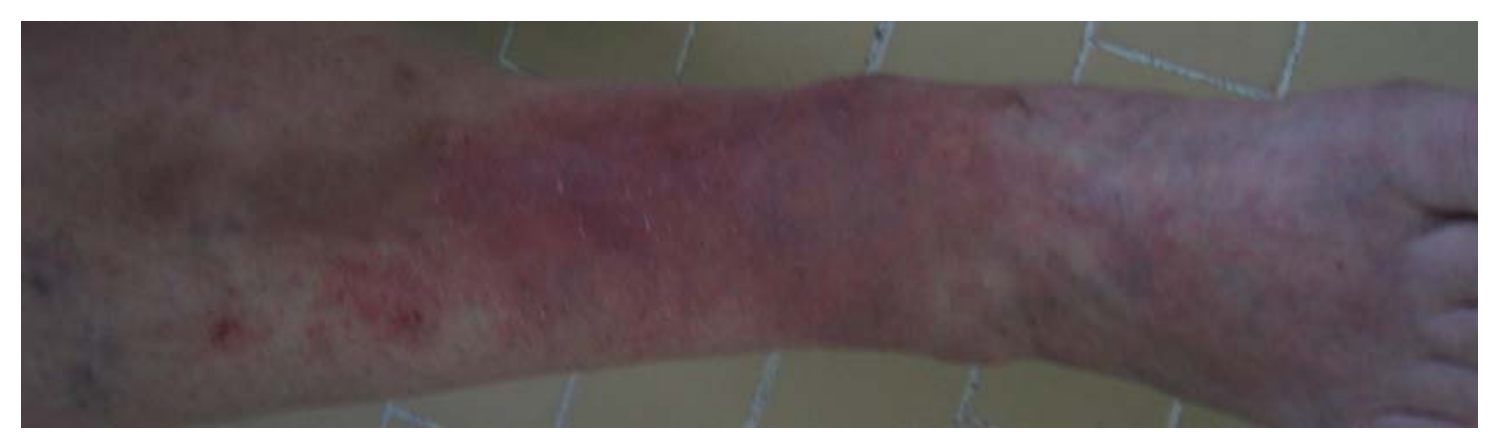

Fig. 4. Erythema developed after implantation prosthesis

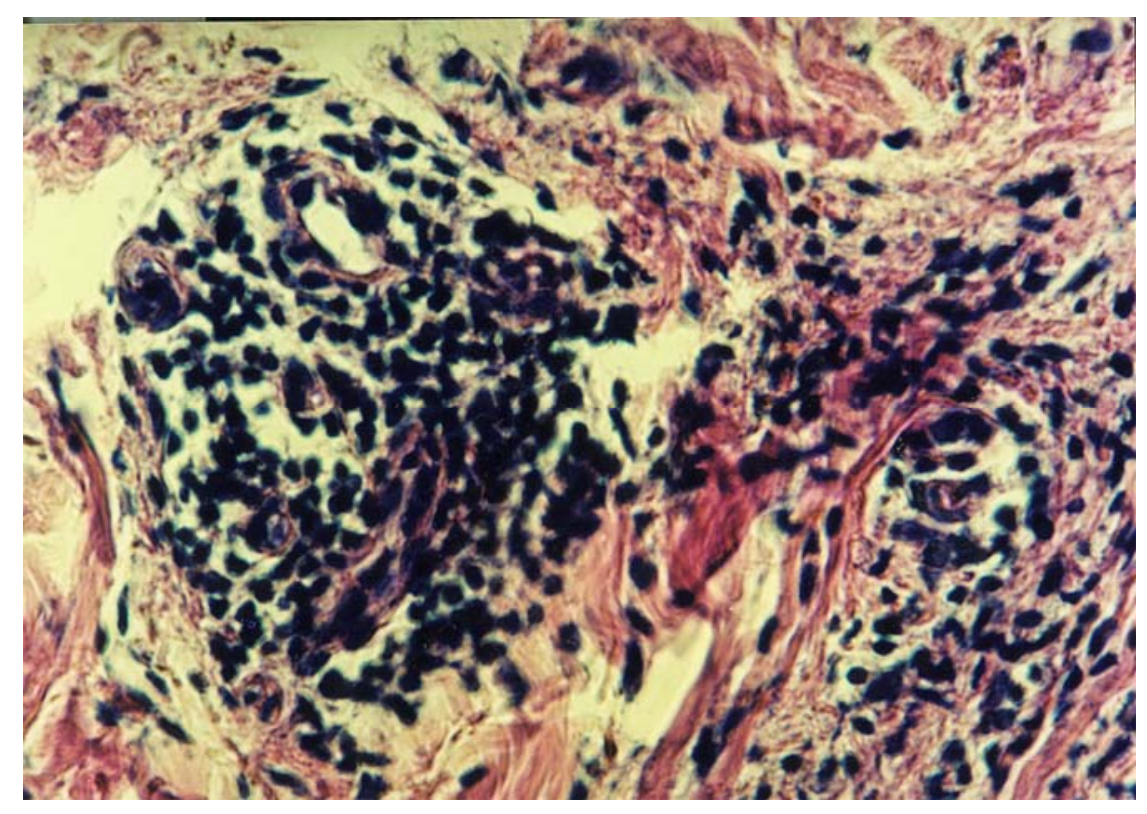

Fig. 5. The photo with histopathological changes 


\section{THE RESEARCH RESULTS AND DISCUSSION}

Literature data on the impact of allergic reactions to the impact on the border of the implant-tissue, do not give a clear answer to the liability component of allergic reactions to the implants as a factor in causing postoperative complications, such as rejecting implant $[8,10,12]$. However, because of the shocking statistic of hypersensitivity to metals in $10-15 \%$ of population $[5,8,9]$ and up to $13 \%$ of positive results to nickel allergy in patch tests among adults, with a significant predominance of women [13] and ever-increasing demand for operations alloplastick arthritis, allergic reactions on the such a large number of people are a serious problem. The risk of allergy complications after the implantation procedure, both from the point of economic and well-being of the patient and makes it worth considering about methods of preventing such situations.

One of the easiest ways to prevent the antireaction of contact allergy to metals in orthopedic-trauma patients directed to treatments alloplastick a medical interview and patch tests, which may protect patients against next complex operation. The studies show that a very important thing is to perform the patch tests on the components of the implants, according to the guidelines of the IDCR. The system allows to perform such tests to diagnose allergies in a fairly long period (96h after the implementation of the test), so increased the accuracy of the analysis of allergy.

For patients who suffer for allergic changes, were observed after surgery implanting prosthetic joints, and anastomoses of long bones, the symptoms resolved after reoperation, which demonstrates the occurrence of complications caused by the action components of the implant on the human body. Early test of oversensitivity, the different metals allows for the selection of metallic biomaterial of which prosthesis, implant, etc. are going to be made for the individual patient's needs, and thus makes you avoid reoperations.

\section{CONCLUSIONS}

Tests done by the author [21] have shown that this type of examination should be done prior to surgery. Performed patch tests, called patch tests have revealed changes in demonstrating the allergenic properties of chromium and nickel. The symptoms of hypersensitivity to these elements in the form of a positive patch test and / or around the fusion reaction followed.

\section{REFERENCES}

1. Śpiewak R.: Contact allergy - diagnostics and it proceed . Allergy of asthma of immunology, 2007, 12 (3), 109-127.

2. Śpiewak R.: Patch testing for contact allergy and allergic contact dermatitis. The Open Allergy Journal, 2008, 1, 42-51.

3. www.tg.net.pl/blog/lisowska.php

4. Sybilski A. Development of disease in atopick period prenatalnym and in early childhood. Borgis - New pediatrics 2/2006, 46-50, www.heel.pl 
5. Szumlański A.: Allergies on nickel, chromium and cobalt at patients. Debate on dsc. degree (doctorate) medical. Military Medical Academy, Łódź 2002

6. Błażejewicz S., Stoch L.: Biocybernetics and biomedical engineering 2000. Volume 4. Biomaterials. Edited by Maciej Nałęcz, Academic Published House EXIT, Warsaw 2003, 5-560.

7. Rudzki E. : ECZEMA II. Metals causing eczema., Alergia 4/15 2002.

8. Szumlański A.: Implantation of a person sensitized implant doped nickel raises implications for as complications., Puls Medicine 6 (55).

9. Hallab NJ, Merritt K, Jacobs JJ: Metal sensitivity in patients with orthopedics implants. J Bone Joint Surg. Am., 83 A, 2001, p. 428-436.

10. Świerczyńska-Machura D. Kieć-Świerczyńska M. Kręcisz B. Pałczyński C. Allergy to components of the implants. Allergy Asthma Immunology 2004, 9 (3), 128-132.

11. Dąbrowska D. Roszkiewicz J. Sosnowski, G., Wójcik T.: Allergy to metal implants used in orthopedics., Advances in Dermatology and Allergology XXIV, 2007 / 2, 99-103.

12. Szumlański A. Buczyłko K., Weiss, W.: Hypersensitivity to nickel, chromium and cobalt as a cause of complications in orthopedic trauma patients. Orthopedics and traumatology at the beginning of the new millennium. Congress of the Polish Society of Orthopedics and Traumatology, Bydgoszcz 2002, 356-359.

13. Czarnobilska E. Obtułowicz K. Wsołek K. Piętowska J. singer, R.: Mechanisms of allergy nickiel., 2007/64/7-8 Medical Review, 502-506

14. Okazaki Y., Gotoh E.: Comparison of metal release from various metallic biomaterials in vitro., Biomaterials 26 (2005), 11.

15. Kanerva L., Forstrom L.: Allergic nickel and chromate hand dermatitis induced by orthopaedic metal implant. Contact Dermatitis 44, 2001, 103-104.

16. Rusinek B., Stobiecka A., Obtułowicz K.: Allergy to titanium and implants, Allergy Asthma Immunology 2008, 5(1), 5-7.

17. High W. A., Ayers R. A., Adams J. R., Chang A., Fitzpatrick J. E.: Granulomatous reaction to titanium alloy: an unusual reaction to ear piercing. J. Am. Acad. Dermatol., 2006, 55(4), 716-720.

18. Budinger L., Hertl M.: Immunologic mechanisms in hypersensitivity reactions to metal irons: an overview. Allergy 2000; 55, 108-115.

19. Piatteli A., Scarano A., Coraggio F., Matarasso S.: Elary tissue reactions to polylacticresorbable membranes: a histological and histochemical study In rabbit. Biomaterials, 1998, 19(10), 889-896.

20. Ciuplik L. A. Kierzkowska Jędrych L.: Biomaterials used to implant Dero: history, present, future., www.lfc.com.pl/pdf/dero3/a4.pdf.

21. Zorn J.: Allergic reactions as a defense of the organism into components of the implants. Thesis, Gdansk University of Technology 2009. 